\title{
A equação de Cambridge e o Novo Teorema de Pasinetti nos modelos pós-keynesianos de crescimento e distribuição de renda
}

\author{
Cambridge Equation and the Neo-Pasinetti Theorem \\ in post-Keynesian models of growth and distribution
}

JOSÉ LUÍS OREIRO*

LUÍS CARLOS G. DE MAGALHAES**

\begin{abstract}
RESUMO: Ao longo deste artigo procuramos avaliar a robustez teórica do assim chamado Novo Teorema de Pasinetti, segundo o qual numa economia na qual a diferenciação entre as propensões a poupar a partir dos lucros e dos salários deve-se a natureza da renda empresarial, não a filiação a uma classe social específica; a taxa de lucro ao longo da trajetória de crescimento de Golden Age é independente da propensão a poupar dos trabalhadores, sendo determinada pelo coeficiente de retenção de lucros das firmas, pela fração do investimento que as empresas desejam financiar com recursos de terceiros e pela taxa natural de crescimento.
\end{abstract}

PALAVRAS-CHAVE: Crescimento e distribuição de renda; Equação de Cambridge; Novo Teorema de Pasinetti.

ABSTRACT: Throughout this article we try to evaluate the theoretical robustness of the socalled New Theorem of Pasinetti, according to which in an economy in which the differentiation between the propensities to save from the profits and the salaries is due to the nature of the business income, not the affiliation to a specific social class; the rate of profit along the Golden Age growth path is independent of workers 'propensity to save, being determined by the firms' profit retention coefficient, by the fraction of the investment firms wish to finance with third-party resources and by the natural rate growth.

KEYWORDS: Growth and distribution; Cambridge Equation; Neo-Pasinetti Theorem. JEL Classification: E11; E12; G11; O42.

\footnotetext{
* Professor Associado do Departamento de Economia da Universidade de Brasília - UNB, Brasília/DF, Brasil e Pesquisador Nível IB do CNPq. E-mail: joreiro@unb.br. ORCID: 0000-0001-8955-8868.

* * Técnico de Pesquisa e Planejamento do Instituto de Pesquisa Econômica Aplicada - IPEA, Brasília/ DF, Brasil. E-mail: luis.magalhaes@ipea.gov.br. ORCID: 0000-0001-8790-099X. Submetido: 1/Outubro/2018; Aprovado: 17/Janeiro/2019.
} 


\section{INTRODUÇÃO}

Um subproduto da abordagem pós-keynesiana para o "dilema Harrod-Domar" foi a assim chamada "equação de Cambridge", também conhecida como "Teorema de Pasinetti” (Lima, 2004, p.12)1. Essa equação estabelecia que a taxa de lucro - ao longo de uma trajetória de crescimento balanceado com pleno-emprego da força de trabalho - numa economia habitada por duas classes de poupadores, e onde apenas uma dessas classes (os capitalistas) obtivesse a totalidade da sua renda na forma de lucros, seria igual a razão entre a taxa de crescimento da força de trabalho e a propensão a poupar dos capitalistas. A propensão a poupar dos trabalhadores seria então irrelevante na determinação da taxa de lucro. Um corolário dessa abordagem é que o conceito neoclássico de produtividade marginal dos fatores de produção não desempenharia nenhum papel na determinação da distribuição de renda entre capitalistas e trabalhadores.

O Teorema de Cambridge suscitou um importante debate na década de 1960. Esse debate foi iniciado com a reação de James Meade (1963, 1966), Samuelson e Modigliani (1966) ao "Teorema de Pasinetti" numa série de artigos publicados entre 1963 e 1966. Esses autores procuraram argumentar que o equilíbrio de longo prazo descrito pela "Equação de Cambridge" seria apenas uma das configurações possíveis da distribuição de renda ao longo da trajetória de crescimento balanceado. Ao lado desse equilíbrio, denominado de "regime de Pasinetti", haveria outro equilíbrio, igualmente geral e simétrico, no qual a relação produto-capital seria determinada pela razão entre a taxa natural de crescimento e a propensão a poupar dos trabalhadores e a taxa de lucro seria independente da "Equação de Cambridge"2. Esse equilíbrio, denominado de "regime Dual" ou "anti-Pasinetti", corresponderia a uma situação na qual os capitalistas seriam "eliminados" do sistema ("eutanásia dos capitalistas”) e a propensão a poupar da sociedade seria, portanto, igual à propensão a poupar dos trabalhadores.

Nesse contexto, o crescimento balanceado com pleno emprego só seria possível se a relação capital-produto atuasse como variável de ajuste entre as taxas garantida e natural de crescimento. Dessa forma, os princípios tradicionais neoclássicos de substitubilidade entre os fatores de produção, produtividade marginal

\footnotetext{
${ }^{1} \mathrm{Na}$ verdade, a "Equação de Cambridge" foi estabelecida inicialmente por Kaldor (1956). Coube a Pasinetti, no entanto, a tarefa de mostrar que a mesma poderia ser obtida sem qualquer referência ao valor da propensão a poupar dos trabalhadores, de forma que a referida propensão seria irrelevante no que toca a determinação da taxa de lucro de equilíbrio ao longo de uma trajetória de crescimento em "Idade Dourada". Dessa forma, alguns autores, incluindo o próprio Pasinetti (1989), preferem a denominação de "teorema de Cambridge" ou "processo Kaldor-Pasinetti". Ao longo do presente artigo iremos considerar os termos "Equação de Cambridge", "Teorema de Pasinetti”, "Processo Kaldor-Pasinetti" e "Teorema de Cambridge” como sinônimos.

${ }^{2}$ No que segue iremos denominar esse resultado de "Teorema Meade-Samuelson-Modligiani” tal como Harcourt (1972, p.222).
} 
decrescente e maximização de lucro se tornariam novamente relevantes para garantir a existência de uma trajetória de crescimento balanceada.

A posição defendida por Pasinetti $(1966,1974)$ era que os problemas de "reversão de técnicas" identificados na controvérsia do capital não só eram suficientes para invalidar a teoria neoclássica da distribuição como também para demonstrar a inexistência do "regime Dual" ou, no melhor dos casos, para mostrar que a ocorrência de um crescimento balanceado sob o "regime Dual" seria possível, mas improvável. Sendo assim, a teoria neoclássica seria incapaz de dar uma resposta satisfatória para o "dilema Harrod-Domar".

A controvérsia entre Pasinetti e Meade-Samuelson-Modigliani foi extensamente analisada no artigo de Oreiro (2005), no qual foi demostrado que: (i) o "Teorema Meade-Samuelson-Modigliani" (teorema MSM) não depende de hipóteses específicas sobre o formato da função de produção, sendo plenamente compatível com os problemas de "reversão de técnicas" apontados na "controvérsia do Capital", os quais só são relevantes para a questão da estabilidade do crescimento em "Idade Dourada" sob o regime Dual ou "anti-Pasinetti"; (ii) o "Teorema de Pasinetti" é, no entanto, mais geral do que o Teorema MSM, pois: (a) permanece válido mesmo após o relaxamento de algumas hipóteses simplificadoras de sua versão original, o que não ocorre com o Teorema MSM; (b) na versão do "Teorema de Pasinetti" feita por Kaldor, o referido teorema permanece válido mesmo no caso de "eutanásia dos capitalistas", ou seja, nas condições de validade do "Teorema MSM".

O "Teorema de Pasinetti" e a possibilidade de "eutanásia" dos capitalistas não foi, contudo, aceita por Nicholas Kaldor (1966). Para esse autor, um dos principais expoentes da assim chamada "Escola de Cambridge", o debate entre Pasinetti e Meade-Samuelson-Modigliani possuía um vício de origem, qual seja, o de identificar a razão da diferenciação entre as propensões a poupar das diferentes classes de renda (salários e lucros) com a diferenciação entre classes sociais (trabalhadores e capitalistas).

Nesse contexto, os “capitalistas" teriam uma propensão a poupar superior à propensão a poupar dos trabalhadores, ou seja, os primeiros tenderiam a poupar uma fração maior da sua renda que os últimos. Kaldor, contudo, não considera convincente a justificativa para essa diferenciação. Com efeito, a mesma parece se basear na velha concepção ricardiana de que os salários tendem ao "nível de subsistência" da força do trabalho. Nessas condições, a acumulação de capital por parte da classe trabalhadora seria impossível e, portanto, faria sentido supor que a propensão a poupar dos trabalhadores é igual a zero (e, obviamente, menor que a propensão a poupar dos capitalistas). Mas não é isso o que Pasinetti assume. De fato, no modelo de Pasinetti os trabalhadores são capazes de acumular capital, pois sua propensão a poupar é maior do que zero. Sendo assim, por que razão então a sua propensão a poupar seria menor do que a propensão a poupar da classe dos "barões hereditários"? Pasinetti nunca deu uma resposta convincente para esta pergunta.

Uma hipótese mais razoável do que a propensão a poupar diferenciada com base na filiação de classe é a hipótese kaldoriana de que a propensão a poupar de- 
pende do tipo de renda. Mais especificamente, Kaldor (1966) supõe que a propensão a poupar a partir dos lucros é maior do que a propensão a poupar a partir dos salários. Essa diferenciação não depende das preferências dos indivíduos que compõe esta ou aquela classe social, mas deve-se à natureza da renda empresarial. De acordo com Kaldor, num mundo no qual prevalecem as economias dinâmicas de escala, as empresas são forçadas pela concorrência a se expandir ou morrer, uma vez que os ganhos de produtividade (e, portanto, a redução de custo de produção) estão relacionados com o aumento da produção ao longo do tempo. Nesse contexto, um elevado coeficiente de retenção de lucros é uma condição necessária para a sobrevivência das firmas no longo prazo, pois os lucros retidos são a fonte primária de financiamento dos planos de expansão das firmas. Famílias, diferentemente de firmas, não estão sujeitas a essa pressão competitiva, razão pela qual podem se contentar com um ritmo mais lento de acumulação de riqueza.

Se a fonte da diferenciação entre as propensões a poupar é origem dos rendimentos e não a filiação a uma classe social específica, então se podem tirar duas consequências importantes para o debate sobre o resultado do "processo de Pasinetti”. Em primeiro lugar, os valores de $s_{c}$ e $s_{w}$ utilizados no cálculo das condições de contorno dos regimes "Dual" e de Pasinetti devem ser reestimados. Mais especificamente, o valor do parâmetro $s_{c}$ deve ser reestimado de 0.20, como suponham Samuelson e Modigliani (1966, p.329) para 0.7 ou 0.8 (Kaldor, 1966, p.312), o que amplia consideravelmente o espaço de validade da "Equação de Cambridge". Sendo assim, as condições de contorno do "regime de Pasinetti" passariam a ser satisfeitas para o caso das economias capitalistas desenvolvidas.

Em segundo lugar, se a diferenciação entre as propensões a poupar não se deve à existência de uma classe social com características específicas - os capitalistas - então mesmo que essa classe seja eliminada do sistema econômico a referida diferenciação continuaria a existir. Dessa forma, poderia ainda ser possível a obtenção da "Equação de Cambridge" por outros meios que não os desenvolvidos por Pasinetti. Essa é a intuição básica do assim chamado "Novo Teorema de Pasinetti" (Neo-Pasinetti Theorem) desenvolvido por Kaldor (1966).

O "Novo Teorema de Pasinetti" (doravante NTP) deu ensejo à crítica de Davidson (1968), para quem Kaldor estaria recuperando o papel da taxa de juros (por intermédio da taxa de valorização das obrigações ${ }^{3}, v$ ) como mecanismo de coordenação entre as decisões de poupança e investimento ao nível de renda de pleno emprego. Dessa forma, a manutenção da diferenciação entre as propensões a poupar entre salários e lucros e a irrelevância da propensão a poupar a partir dos salários seriam obtidas à custa de um retorno à "lei de Say" e a ideia de que a poupança determina o investimento.

\footnotetext{
${ }^{3}$ No trabalho original de Kaldor (1966) as empresas emitem somente ações, como ativos financeiros que compõe o portfólio das famílias. Aqui se utiliza a expressão "obrigações" ou "títulos" para indicar um conjunto de ativos financeiros mais amplo (debêntures, letras comerciais e outros títulos emitidos pelas empresas).
} 
A crítica de Davidson levou Lavoie (1998) a reapresentar o NTP no contexto dos modelos neo-kaleckianos de crescimento e distribuição de renda, desenvolvidos no início dos anos 1980, a partir do trabalho seminal de Rowthorn (1981). Nesse contexto, Lavoie (Ibidem, p.429) argumenta que a introdução da taxa de valorização dos títulos emitidos pelas empresas $v$, não afeta o resultado keynesiano básico no sentido da causalidade do investimento para poupança; assim como o resultado neo-kaleckiano básico de que a elevação da participação dos salários na renda aumenta a taxa de lucro. Dessa forma, a crítica de Davidson não se sustentaria: a introdução da variável $v$ não seria uma concessão à teoria econômica neoclássica, pois mesmo que as firmas tenham um comportamento em relação à sua estrutura de capital determinado pela taxa q-Tobin, o regime de crescimento do NTP manteria as características keynesianas básicas, particularmente a determinação da poupança pelo investimento.

A solução de Lavoie (1998) para o NTP gerou, mais recentemente, um debate a respeito da especificação da função investimento. Os modelos neo-kaleckianos de crescimento e distribuição de renda se baseiam na ideia de que o grau de utilização da capacidade produtiva é uma variável endógena que se ajusta em face de mudanças na demanda agregada. Essa endogeneidade, por sua vez, é a contrapartida necessária da baixa sensibilidade do ritmo de acumulação de capital às divergências entre o grau efetivo e desejado de utilização da capacidade produtiva. Essa baixa sensibilidade da acumulação de capital faz, contudo, que o grau de utilização da capacidade produtiva seja hipersensível às variações dos parâmetros do modelo, particularmente às variações na propensão a poupar (Skott, 2010). Esse "excesso de sensibilidade" do grau de utilização da capacidade produtiva não parece estar em acordo com o comportamento empiricamente observado dessa variável.

Isso posto, o presente artigo tem por objetivo fazer um mapeamento e avaliação do debate a respeito do NTP procurando mostrar em que medida os resultados básicos do referido teorema são robustos (ou não) às críticas feitas por Davidson (1968) e Skott (2010). Para tanto, o artigo está estruturado em seis seções, incluindo a introdução. Na segunda seção iremos apresentar a derivação do NTP por Kaldor (1966). A seção seguinte apresenta as críticas de Davidson (1968) ao NTP. A quarta seção está dedicada à formulação do NTP nos termos de um modelo neo-kaleckiano de crescimento e distribuição de renda feita por Lavoie (1998). A quinta seção apresenta as críticas de Skott (2010) à especificação da função investimento nos modelos neo-kaleckianos e a sexta seção faz um balanço do debate em torno do NTP.

\section{KALDOR, A "EQUAÇÃO DE CAMBRIDGE” E O "NOVO TEOREMA DE PASINETTI"}

No apêndice do artigo publicado em 1966, Kaldor elabora o que denominou de "Teorema Neo-Pasinetti" (ou Novo Teorema de Pasinetti, NTP) no qual ele procura demonstrar que a "Equação de Cambridge" pode ser obtida sem se supor a 
existência de uma "classe de barões hereditários" com elevada propensão a poupar, a quem Pasinetti (1961) denominava de "capitalistas". Dessa forma, a sua eventual eliminação do sistema - ou seja, a "eutanásia do capitalista" - como resultado do "processo de Pasinetti" não eliminaria a diferenciação entre a propensão a poupar a partir dos lucros e dos salários, essencial para a solução pós-keynesiana do "dilema de Harrod". Com efeito, ao avaliar a crítica de Samuelson e Modigliani à "Equação de Cambridge", Kaldor afirma que:

"Samuelson and Modigliani assume that any macroeconomic theory which makes use of the notion of differences in savings propensities between profits and wages requires an identifiable class of hereditary barons - a class of capitalists with 'permanent membership' - distinguished by a high savings propensity and of a "permanent" class of workers distinguished by a low savings propensity. I cannot of course speak for Dr. Pasinetti, but as far as my own ideas are concerned, I have always regarded the high savings propensity out of profits as something which attaches to the nature of business income, and not to the wealth (or other peculiarities) of the individuals who own the property. It is the enterprise, not the particularly body of individuals owning it at one time, which finds it necessary, in a dynamic world of increasing returns, to plough back a proportion of the profits earned as a kind of 'prior charge' on earnings in order to ensure the survival of the enterprise in the long run" $(1966$, p.310).

Para mostrar que a "Equação de Cambridge" pode ser deduzida de um arcabouço teórico onde a diferenciação entre as propensões a poupar a partir de lucros e salários não seja dependente da existência de uma "classe capitalista", consideremos uma economia na qual os trabalhadores poupam uma fração $s_{w}$ de suas rendas (W) para financiar o seu consumo na aposentadoria. Essa poupança é assim a fonte primária da demanda por títulos de dívida ou obrigações que as empresas emitem no mercado primário para obter recursos externos para o financiamento dos seus planos de investimento. Os trabalhadores aposentados dessa economia consomem uma fração $\bar{c}$ dos "ganhos de capital" $G$ proporcionados pelos títulos de dívida eles compraram enquanto ainda estavam trabalhando. Por fim, as empresas financiam uma proporção $i$ do seu investimento planejado $g K$ com a venda de obrigações no mercado primário, onde $g$ é a taxa desejada de crescimento do estoque de capital que pode ou não ser igual a taxa natural de crescimento da economia (Harcourt, 1972, p. 229) e K é o valor do estoque de capital das firmas. O equilíbrio no mercado primário de obrigações exige que:

$$
s_{w} W=\bar{c} G+i g K
$$

Defina-se $v$ como sendo a razão de valorização, ou seja, a razão entre o valor de mercado das obrigações emitidas pelas empresas e o valor do capital empregado pelas firmas. Temos, então, que: 


$$
v=\frac{p N}{K}
$$

Onde: $p$ é o preço de mercado dos títulos de dívida; $N$ é quantidade de títulos emitidos, $K$ é o valor do estoque de capital.

A dinâmica da razão de valorização é dada pela seguinte equação diferencial:

$$
\frac{(\dot{p} N+\dot{N} p) K-\dot{K} p N}{K^{2}}
$$

Supondo que a razão de valorização é constante ao longo do tempo, ou seja, que a economia se encontra numa posição de equilíbrio de steady state, e definindo os ganhos de capital sobre os títulos de dívida $(G)$ como $G=N \dot{p}$, temos que:

$$
G=v \dot{K}-p \dot{N}
$$

Sabemos que:

$$
\begin{aligned}
& \dot{K}=g K \\
& p \dot{N}=i g K
\end{aligned}
$$

Substituindo (5) e (6) em (4), temos que:

$$
G=(v-i) g K
$$

Substituindo (7) em (1), temos que:

$$
s_{w} W-c(v-i) g K=i g K
$$

A equação (8) estabelece que o fluxo de oferta de obrigações no mercado primário $(\operatorname{IgK})$ deve ser igual à demanda líquida de obrigações dos "fundos de pensão", igual à poupança dos trabalhadores da ativa menos a despoupança dos trabalhadores aposentados.

Adicionando o investimento autofinanciado pelas empresas em ambos os lados da equação (8) temos que:

$$
s_{w} W-c(v-i) g K+(1-i) g K=g K
$$

Como, por definição, $(1-i) g K=S_{C} P$, onde $S_{C}$ é o coeficiente de retenção de lucros das firmas e $P$ é a massa de lucros, temos que:

$$
s_{w} W-c(v-i) g K+s_{c} P=g K
$$

Sabemos que $W=Y=P$, onde $Y$ é a renda nacional e $P=r K$, onde $r$ é a taxa de lucro. Após alguma manipulação algébrica da equação (10), podemos deduzir a seguinte expressão:

$$
\frac{s_{w}}{g} \frac{Y}{K}-\left(s_{c}-s_{w}\right) \frac{r}{g}-c(v-i)=1
$$


Adotando procedimento análogo para a equação (8), obtemos que:

$$
\frac{s_{w}}{g} \frac{Y}{K}-s_{w} \frac{r}{g}-c(v-i)=i
$$

Substituindo (12) em (11), obtemos a seguinte expressão:

$$
r=(1-i) \frac{g}{s_{c}}
$$

A equação (13) estabelece que a taxa de lucro é uma função apenas da taxa desejada de crescimento do estoque de capital, da fração do investimento que é autofinanciada e do coeficiente de retenção de lucro por parte das firmas $\left(s_{c}\right)$. A propensão a poupar dos trabalhadores e dos "capitalistas" não tem nenhuma influência sobre a taxa de lucro das firmas ao longo da trajetória de crescimento de steady state.

Nesse contexto, Kaldor afirma que:

"The rate of profit in a golden age equilibrium [...] will depend only on g, and $I$, and then will be independent of the 'personal' savings propensities and $c$. In this way it is similar to the Pasinetti Theorem in that the rate of profit will be independent of (and also $c$ ) but it is reached by a different route; it will hold in any steady growth state, and not only in a 'long run 'Golden Age'; it does not postulate a class of hereditary capitalists with a special high-savings propensity. In the special case $i=0$, it reduces to the simple Pasinetti formula, $r=\frac{g}{s_{c}} "(1966, \mathrm{p} .318)$.

\section{A CRÍTICA DE DAVIDSON AO NOVO TEOREMA DE PASINETTI.}

Davidson (1968) elabora uma bem fundamentada crítica ao NTP, a partir da constatação de que o mecanismo de ajuste no mercado primário de títulos da dívida das firmas proposto por Kaldor envolve o restabelecimento da taxa de juros como mecanismo de ajuste entre as decisões de poupança e investimento. Dessa forma, o NTP seria equivalente ao retorno da "lei de Say", ou seja, da ideia de que as economias de mercado possuem mecanismos automáticos de ajuste da demanda agregada ao nível de renda de pleno-emprego. Nas suas palavras:

"If accepted at face value, Kaldor's statement is truly a surprising volte-face Keynesian theory, especially since it is a Keynesian of Kaldor's stature who appears to be implying that given the distribution of income, given the level of net investment $(I)$, and given the corporate new issue policy, the level of security price (i.e. the rate of interest) will cause aggregate personal consumption to just fill the gap between the full employment level of output and investment spending. After all these years of verbal duels, acrimony, and clarification, Kaldor's analysis suggests that the rate of interest is the mechanism which ensures that effective demand is always maintained at the full employment level” (1968, p.259). 
Na análise de Davidson, o NTP teria sido mal formulado por Kaldor, uma vez que esse autor não teria feito a distinção, crucial para a teoria keynesiana, entre as decisões de composição de portfólio e de poupança das famílias. Dessa forma, Kaldor teria considerado em sua análise apenas o mercado primário de títulos de dívida das empresas, ignorando totalmente a existência de um mercado secundário de obrigações e, portanto, o papel da demanda (não especulativa) de títulos da dívida como reserva de valor por parte das famílias.

No mercado secundário de obrigações as famílias podem rever continuamente a composição de sua riqueza entre os diversos ativos disponíveis, em particular, podem rever a fração da sua riqueza que é alocada na forma de títulos de dívida das empresas. Como as obrigações negociadas no mercado primário são substitutos perfeitos das obrigações negociadas no mercado secundário; segue-se que a demanda total por obrigações é composta, não apenas pela demanda por novas obrigações derivada da poupança líquida das unidades familiares; mas também da fração do estoque total de riqueza que as famílias desejam manter, num dado ponto do tempo, na forma de títulos de dívida das empresas.

Analogamente, no lado da oferta, temos que a oferta total de obrigações é composta pelo estoque de obrigações emitidas no passado, acrescido do fluxo de oferta de novas obrigações ${ }^{4}$. Nesse contexto, a razão de valorização (ou a taxa de juros) é determinada de forma a equalizar a demanda total de obrigações com a oferta disponível das mesmas. Se ao valor de equilíbrio de $v$ a demanda de novas obrigações for superior (inferior) à oferta de novas obrigações; então a poupança desejada pelas famílias será maior (menor) do que o investimento planejado pelas empresas dando ensejo a mudanças na distribuição de renda entre salários e lucros, caso a economia esteja operando com pleno emprego da força de trabalho; ou a mudanças no nível de renda e de emprego, caso a economia esteja operando com subutilização da capacidade instalada.

A demanda (não especulativa) por obrigações como reserva de valor é dada pela seguinte expressão:

$$
D_{p}=\delta\left(p_{p}, \rho, \beta, \gamma, e\right) V
$$

Sendo: $\frac{\partial D_{p}}{\partial p_{p}}<0 ; \frac{\partial D_{p}}{\partial \rho}>0 ; \frac{\partial D_{p}}{\partial \beta}<0 ; \frac{\partial D_{p}}{\partial \gamma}<0 ; \frac{\partial D_{p}}{\partial e}>0$

Onde: $D_{p}$ é a quantidade demandada de títulos de dívida das firmas; $\delta($.) é a fração da riqueza financeira que as famílias desejam manter na forma de obrigações; $V$ é o valor da riqueza financeira das famílias (igual à soma do valor dos sal-

\footnotetext{
${ }^{4}$ Esse ponto foi pioneiramente ressaltado por Townsend (1937). Nas suas palavras: "For it is an essential part of Mr. Keynes's theory of interest that the rate of interest [...] is not causally determined by the conditions of supply and demand (for new loans) at the margin. Rather are the demand and supply schedules for new loans determined by the value set by the market on existing loans (of similar type)" (Townsend, 1937, p.157).
} 
dos monetários retidos como reserva de valor e o valor de mercado das obrigações retidas num dado ponto do tempo); $p_{p}$ é o preço de mercado das obrigações; $p$ é a taxa esperada de variação dos preços das obrigações; $\beta$ é o grau de aversão ao risco renda; $\gamma$ é o grau de aversão ao risco de perda de capital; $e$ é o número de possuidores de riqueza.

Num dado ponto do tempo, o estoque de obrigações é herdado do passado, de forma que a oferta de obrigações no mercado secundário é inelástica e dada por:

$$
S_{p}=\alpha
$$

Dado o estoque de riqueza $V$ e o estoque de obrigações $\alpha$, o preço de mercado dos títulos da dívida das firmas será determinado no ponto em que as curvas de demanda e oferta de obrigações no mercado secundário se interceptarem (figura 1).

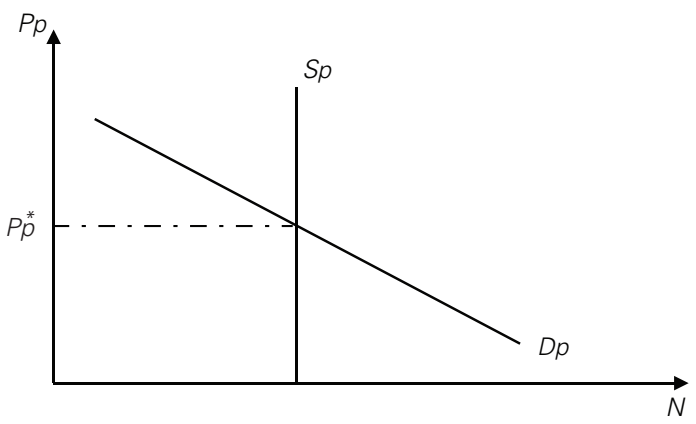

Ao longo do tempo, a demanda e a oferta de obrigações são alteradas em função da acumulação de riqueza por parte das famílias devido à poupança por elas realizadas e à emissão de obrigações por parte das empresas para obter financiamento externo para os seus planos de investimento.

Seja i a fração do investimento planejado pelas firmas que é financiado com recursos de terceiros por intermédio da venda de títulos de dívida no mercado primário. O fluxo de novas emissões $\left(s_{p}\right)$ é dado por:

$$
s_{p}=\frac{i g K}{p_{p}}
$$

A variação da demanda (não-especulativa) de obrigações é dada por:

$$
\Delta D_{p}=\delta(.) \Delta V=\delta(.)\left[s_{W} W-c G\right]
$$

Igualando (16) e (17) temos que:

$$
\delta(.)\left[s_{w} W-c G\right]=\frac{i g K}{p_{p}}
$$

A equação (18) apresenta a condição de equilíbrio no mercado de obrigações. A simples inspeção da equação (18) mostra que não há nenhuma razão para que o equilíbrio no mercado de obrigações imponha que $\left[s_{w} W-c G\right]=i g K$. É possível tanto uma 
situação na qual $\left[s_{w} W-c G\right]=i g K$, ou seja, uma situação na qual a poupança planejada das famílias seja superior ao investimento que as empresas desejam financiar com recursos externos; como uma situação na qual $\left[s_{w} W-c G\right]=i g K$, isto é, uma situação na qual a poupança planejada pelas famílias seja menor do que o investimento que as firmas desejam financiar com capital de terceiros. No primeiro caso, a demanda agregada será menor que o nível de produção de pleno emprego, o que dará ensejo a uma redução de preços e margens de lucro, gerando assim uma redistribuição de renda dos lucros para os salários.

O aumento da participação dos salários na renda nacional irá reduzir a poupança das famílias - via redução de $r$ na equação (12) — até o ponto em que a poupança desejada pelas mesmas se iguale com a demanda de recursos de terceiros por parte das firmas. No segundo caso, a demanda agregada será maior que o nível de produção de pleno emprego, dando origem a uma elevação de preços e margens de lucro, o que terminará por redistribuir renda dos salários para os lucros. O aumento da participação dos lucros na renda irá aumentar a poupança das famílias - via aumento de $r$ na equação (12) — até o ponto em que a poupança desejada pelas mesmas se iguale com a demanda por financiamento externo por parte das firmas.

Nesse contexto, Davidson conclui que:

"The analysis has shown that given saving propensities of the various income classes $[. .$.$] , then the price of placements will alter until the hou-$ sehold sector absorbs into its portfolio all the securities offered to it. The change in placements prices (and therefore in the rate of interest) does not in itself affect the total of personal savings or the distribution of savings between workers and capitalists $[\ldots]$

Nevertheless, it is either changes in output (at less than full employment) or inflationary changes in wages and prices at full employment which constitutes the prime channels for working the appropriate changes in the level of personal savings to bring it into equilibrium with the exogenously determined level of investment" (1968, p.268).

\section{LAVOIE E O NOVO TEOREMA DE PASINETTI NO MODELO NEO-KALECKIANO}

As críticas de Davidson (1968) levaram a Lavoie (1998) a revisitar o NTP com objetivo de mostrar que os resultados básicos do NTP continuavam válidos mesmos nas condições que a variável $v$, semelhante à taxa q-Tobin, operava como um mecanismo de equalização de poupança e investimento. Lavoie faz a defesa do NTP - em um contexto que as famílias apresentam ganhos de capital por carregar títulos das firmas em seus portfólios de riqueza - com a introdução de uma equação de investimento independente, que permite endogeneizar conjuntamente a taxa de 
acumulação de capital e a taxa de utilização de capacidade produtiva, conforme a tradição dos modelos neo-kaleckianos.

O primeiro passo de Lavoie é refazer a apresentação do NTP no quadro de um modelo neo-kaleckiano-padrão, com objetivo de recuperar os resultados kaldorianos de independência da taxa de lucro dos hábitos de poupança da classe trabalhadora; assim como mostrar a importância dos ganhos de capital para a poupança e despoupança das famílias não afetava o resultado keynesiano básico da poupança se ajustar ao nível de investimento. Desse modo, a equação (19) representa a taxa de crescimento do produto que é compatível com o equilíbrio no mercado de bens.

$$
g=s_{w}\left[(u / k-r)+\left(1-s_{c}\right) r\right]-\left(1-s_{w}\right)(v-x) g+s_{c} r
$$

A definição das variáveis e parâmetros da equação (19) são as seguintes: $g$ é a taxa de crescimento do produto; $s_{w}$ é a propensão a poupar das famílias; $k$ é a razão capital/produto de plena capacidade; $r$ a taxa de lucro; $v$ é a taxa de valorização dos ativos financeiros; $s_{c}$ é a taxa poupança das firmas e considerada constante; $x$ é a proporção da estrutura de capital da firma que é financiada por fontes externas, emissão de títulos da dívida por parte das firmas e é considerada constante. Lavoie ainda faz a suposição importante para recuperar o NTP no quadro dos modelos neo-kaleckianos: as famílias em idade ativa apresentam uma taxa de crescimento demográfico e uma taxa de crescimento da renda familiar per capita superior ao das famílias em idade inativa.

A interpretação dos termos da equação (5) é a seguinte: o termo $(\mathrm{u} / \mathrm{k}-\mathrm{r})$ representa a poupança derivada dos salários; o termo $\left(1-s_{c}\right)$ é a poupança dos rendimentos dos ativos financeiros dos portfólios das famílias ativas no mercado de trabalho; o termo $\left(1-s_{w}\right)(v-x) g$ é a despoupança das famílias em idade inativa; e, por fim o termo $\left(s_{c} r\right)$ são os ganhos retidos pelas firmas. A equação (19), chamada de reta ED, descreve o equilíbrio no mercado de bens. Portanto, é o loci das combinações entre a taxa de lucro $r$ e a taxa de valorização $v$ para os quais a demanda efetiva é igual ao nível de produção e não existe capacidade ociosa não planejada.

Pode-se derivar uma segunda equação para o equilíbrio no mercado financeiro, em que o fluxo de oferta de títulos de dívida das firmas se iguala à sua demanda, conforme é apresentado na equação (20) abaixo. Nessa equação, chamada de reta FM, os termos à esquerda expressam a oferta de títulos que é decomposta em duas parcelas. A primeira parcela $(x g)$ é a oferta de títulos decorrente de novas emissões por parte das empresas (mercado primário). O segundo componente, $\left(1-s_{w}\right)(v-x) g$ é a oferta de títulos já emitidos pelas empresas (mercado secundário) e que fazem parte do portfólio das famílias em idade inativa (aposentados). Portanto, essas famílias estão despoupando seu estoque de riqueza.

$$
x g+\left(1-s_{w}\right)(v-x) g=s_{w}\left[(u / k-r)+\left(1-s_{c}\right) r\right]
$$

Os termos à esquerda da equação (20) podem também ser decomposto em dois componentes. O primeiro é a demanda por títulos por parte das famílias que é com- 
posta da renda poupada derivada dos salários percebidos, e um segundo componente que é a renda poupada em razão das empresas pagarem as famílias em idade ativa um fluxo de rendimentos pelas obrigações que elas mantêm no seu portfólio de riqueza.

As equações (19) e (20) podem ser manipuladas de forma a isolar a taxa de lucro $r$ de forma que podem ser reescritas como:

$$
\begin{aligned}
& r=\left\{g\left[1+\left(1-s_{w}\right)(v-x)\right]-s_{w} u / k\right\} /\left[s_{c}\left(1-s_{w}\right)\right] \\
& r=\left\{-g\left[\left(1-s_{w}\right)\left(v+x s_{w}\right)\right]+s_{w} u / k\right\} / s_{w} s_{c}
\end{aligned}
$$

A equação (21), reta ED, tem inclinação positiva, pois quando a taxa de lucro $r$ se eleva, em equilíbrio, o incremento da taxa de valorização v deverá compensar o seu crescimento, portanto, ocorrerão ganhos de capital, o que incentivará a compra de novos títulos para as carteiras de ativos das famílias. A emissão de novos títulos será utilizada para o financiamento da expansão das firmas, por meio da elevação dos investimentos financiados por fundos internos, e, consequentemente, acarretará a elevação da taxa de crescimento do produto.

A equação (22), reta FM, tem inclinação negativa, pois o aumento da taxa de lucro $r$ levará a redução da participação das famílias na renda. Essa mudança na distribuição na renda reduzirá a demanda por títulos das empresas. Portanto, a redução da demanda por títulos das empresas vai impactar negativamente o preço desses títulos e, consequentemente, a taxa de valorização $v$.

O equilíbrio simultâneo dos valores da taxa de lucro $r$ e a taxa de valorização $v$ é dado pelo sistema de equações (21) e (22) que nada mais são que os resultados básicos do TNP.

$$
\begin{aligned}
& r^{*}=g(1-x) / s_{c} \\
& v^{*}=s_{h}(u / g k-1) /\left(1-s_{w}\right)
\end{aligned}
$$

O mecanismo de equilíbrio do mercado de bens, curva ED, é a variação da taxa de lucro $r$; no mercado de títulos das empresas, curva FM, vai ser alterações na taxa de valorização $v$. Note-se a equação (23) reafirma o resultado original de Pasinetti (1962) no qual a taxa de lucros $r$ só depende da taxa de crescimento da economia $g$; da proporção $x$ do investimento que é financiado pela emissão títulos de dívida pelas firmas; e, da fração $s_{c}$ de retenção dos lucros para financiar a expansão das firmas. Essas duas últimas variáveis são de decisão das firmas.

Desse modo, a poupança dos trabalhadores e dos capitalistas não afeta a taxa de lucro e esse resultado não depende dos pressupostos da teoria neoclássicos em relação ao grau de substituição entre fatores, a tecnologia de produção e a escassez dos fatores de produção, de forma a validar a generalidade do NTP. A análise, portanto, deve se centrar nos determinantes da taxa de crescimento da economia $g$, pois a taxa de lucros $r$ e a taxa de valorização $v$ se ajustam a essa taxa. $\mathrm{O}$ 
passo seguinte, característico dos modelos de crescimento de extração pós-keynesiana, é introduzir uma equação de investimento independente para determinar a taxa de acumulação da economia.

Os mecanismos de equilibro no regime Neo-Pasinetti pode ser analisado com ajuda da Figura 2 (Lavoie, 1998, p.422), que relaciona a reta FM, que descreve o equilíbrio no mercado de bens, e a reta ED, que descreve o equilíbrio no mercado de ativos financeiros (títulos de dívida das firmas). O deslocamento das curvas ED e FM dependem da variação de g, portanto, quando se eleva a taxa de crescimento da economia, a reta ED se desloca para cima da sua posição original e a reta FM se desloca para baixo da sua posição original.

É ainda introduzida uma reta NP que relaciona a taxa de crescimento da economia g com a taxa de lucro $r$, portanto, essa taxa cresce na mesma proporção que aumenta a taxa g. É suposto ainda no regime de crescimento Neo-Pasinetti que a taxa de utilização u seja constante.

Dessa forma, se a taxa g de crescimento da economia se acelera, passa de $g_{1}$ para $\mathrm{g}_{2}$ então a curva FM se desloca para baixo, o que implica que a taxa de valorização v" dos títulos carregados pelas firmas no mercado financeiros vai se reduzir de $v^{\prime \prime}{ }_{1}$ para $v^{\prime \prime}{ }_{2}$. Ou seja, a aceleração da taxa de acumulação determina que as firmas elevarão a emissão de títulos da dívida para financiar sua expansão com impacto negativo nos seus preços, o que, por sua vez, reduzirá a taxa de valorização $v$, conforme mostra a Figura $2^{5}$.

\section{Figura 2}

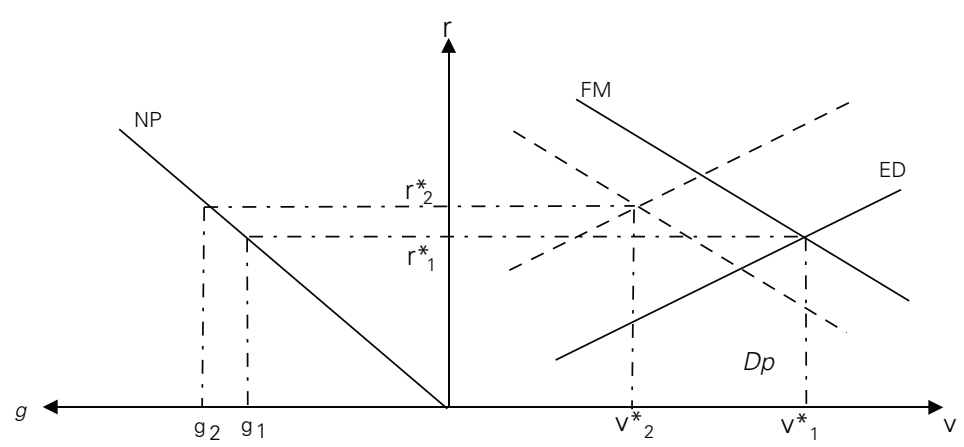

O impacto da taxa de acumulação $g$ na taxa de lucro $r$ será positivo ${ }^{6}$. Entretanto, dois mecanismos de ajustamento podem ser considerados na explicação do efeito da aceleração da taxa de acumulação $g$ na elevação da taxa de lucro. O primeiro mecanismo é tradicional nos modelos de extração de Cambridge: mudanças na redistribuição na renda entre salários e lucros. Em uma economia oligopolizada com preços formados por regras de mark-up, o aumento da taxa de crescimento da economia possibilita a elevação de preço das firmas e das margens de lucro e, consequentemente, a participação dos lucros no produto $(P / Y)$.

\footnotetext{
${ }^{5}$ A derivada em relação a g na equação 20 é menor que zero, ou seja, $\frac{d v}{d g}<0$.

${ }^{6}$ A derivada em relação a g na equação 19 é maior que zero, ou seja, $\frac{d r}{d g}=(1-x) / s_{c}>0$.
} 
Um segundo mecanismo para explicar o efeito positivo da aceleração da taxa de acumulação da economia na taxa de lucro é comum aos modelos de extração neo-kaleckiana: a endogeneização da taxa de utilização da capacidade u. Esse mecanismo leva ao aumento da taxa de lucro $(P / K)$ sem impor a elevação das margens de lucros das firmas, portanto, não requer alteração na distribuição funcional de renda. O resultado - padrão nos modelos neo-kaleckianos - é que a taxa de lucros da economia cresça com aumento da participação dos salários na renda.

O exame mais formal desses dois mecanismos pelos quais a taxa de crescimento da economia afeta positivamente a taxa de lucro parte da equação (25). Nessa equação a taxa de lucro $r$ pode ser expressa como em função de três variáveis: $m$ que é a participação dos lucros na renda, $u$ que é taxa de utilização da capacidade e a relação capital produto $k$.

$$
r=m u / k \text {. }
$$

Nos modelos de crescimento de Cambridge se assume que o grau de utilização da capacidade produtiva é constante e igual ao nível normal, $u_{n, \text {, }}$ Desse modo, a margem de lucro $m$ é o mecanismo de ajustamento pela qual a firma fixa a taxa de lucro necessária para seu processo de expansão, dado as condições de concorrência da sua estrutura de mercado. Usando as equações (23) e (24), então a margem de lucro pode ser escrita como:

$$
m^{*}=g k(1-x) / s_{c} u_{n}
$$

Portanto, a aceleração da taxa de acumulação da economia requer a elevação da taxa de lucros, que impõe o crescimento das margens de lucros das firmas. Ou seja, a maior taxa de acumulação da economia só pode ser obtida por meio da alteração da distribuição funcional da renda com a compressão dos salários. Nesse caso, o processo de acumulação resulta em um conflito distributivo que reduz a participação dos salários na renda nacional.

O mecanismo de ajustamento por aumento da margem de lucro, da taxa de lucro e da taxa de crescimento pode ser visto nos dois primeiros gráficos da Figura 3 (Lavoie, 1998, p.424). A elevação da taxa de lucro implica o deslocamento da função de mark-up de PC1 para PC2 em razão da elevação da taxa de mark-up, supondo que a utilização de capacidade é constante. Isto possibilitará a firma elevar os lucros retidos para compatibilizar seu investimento com uma maior taxa de crescimento da economia.

Outro mecanismo de compatibilizar a elevação da taxa de lucro com a aceleração da taxa de acumulação é por meio de alterações na taxa de utilização da capacidade sem alteração na margem de lucro, conforme prescreve o modelo neo-kaleckiano-padrão. A presença de estruturas de mercados olipolizadas exige a existência de capacidade ociosa, que opera como uma variável competitiva para impedir a entrada de concorrentes. A manutenção de capacidade ociosa é um instrumento concorrencial das firmas nas estruturas de mercado. 
Figura 3

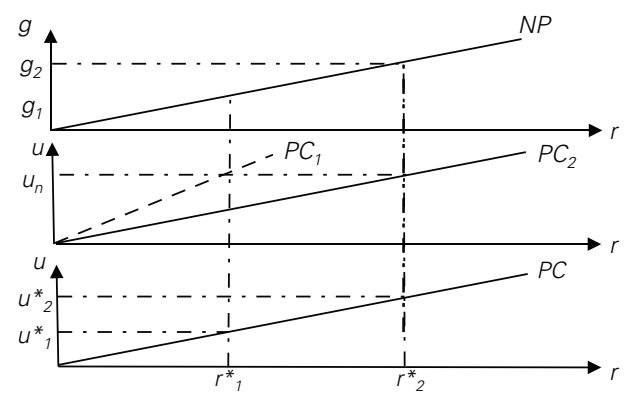

Dessa forma, a taxa de utilização pode variar para se compatibilizar com a taxa de lucro requerida para expansão da firma. Nesse caso, o fechamento do modelo de crescimento do NTP ocorrerá pela taxa de utilização da capacidade, conforme o modelo neo-kaleckiano canônico. Considerando as equações (23) e (24), a taxa de utilização é a variável de fechamento modelo e, portanto, a taxa $u$ compatível com a taxa de lucro requerida para expansão das firmas é dada pela equação (27).

$$
u^{*}=g k(1-x) / s_{c} \mathrm{~m}
$$

Essa condição pode ser vista no último gráfico (de cima para baixo) da Figura 3. A taxa de lucro requerida se ajusta por meio do aumento da taxa de utilização da capacidade das firmas. A função de mark-up não se altera, mas as firmas conseguem aumentar as taxas de lucro sem elevar as margens de lucro e a taxa de mark-up.

Deve ser ressaltado que o resultado do NTP, de que a taxa de lucro depende da propensão a poupar das firmas e da taxa de crescimento da economia, é compatível com o fechamento do modelo por meio da taxa de utilização da capacidade, assim como também pela alteração da taxa de lucro da economia. Portanto, o teorema seria compatível com as duas classes de modelos pós-keynesianos, que podem ainda supor a formação de preços por meio do custo marginal em mercados competitivos, ou por regra de mark-up em mercados oligopolizado. Desse modo, Lavoie recupera a elevada generalidade do NTP, poucas vezes encontrada em teoria econômica.

A questão que fica em aberto no NTP é a determinação da taxa de acumulação da economia $\left(g^{i}=I / K\right)$. A solução dada na tradição de Cambridge é que a função de investimento depende da taxa de lucro esperada e da taxa efetivamente realizada no longo prazo. Portanto, a função de investimento pode ser representada pela equação (28).

$$
g^{i}=\gamma+g_{u} r
$$

Onde $\gamma$ e g $g_{u}$ são, respectivamente, o "animal spirits" dos empresários - parâmetro que expressaria o grau de confiança no estado da economia e das suas expectativas -, e a propensão dos bancos de expandir o crédito. A vantagem desse 
modelo, segundo Lavoie (1998, p.425), é que pode ser resolvido de forma recursiva. Portanto, a função de investimento (28) intercepta a reta NP, em steady state, no primeiro gráfico da Figura 3, de modo que $g^{i}=g$.

Outra solução é a especificação da função de investimento com o grau de utilização da capacidade, típica dos modelos de extração neo-kaleckiana. O argumento econômico para incorporar a taxa de utilização como variável da função de investimento é que flutuações de demanda podem levar as firmas a perder participação de mercado se não contam com uma reserva de capacidade. Desse modo, as firmas teriam sistematicamente um incentivo ao investimento na medida em que a taxa de capacidade se eleva em relação à média histórica de sua utilização. Essa taxa teria um componente autorregressivo em razão da concorrência intercapitalista. A função de investimento neo-kaleckiana pode ser especificada como na equação (29) a seguir:

$$
g^{i}=\gamma+g_{u} u
$$

A contrapartida da função de investimento, expressa pela equação (29), por sua vez, é a função poupança dada pela equação (22); na qual a taxa de lucro é determinada pela taxa de crescimento da economia $g$, a proporção do investimento que é financiado por fontes de recursos externas à firma (emissão de títulos da dívida) e, ainda, a propensão das firmas em reter fundos internos a partir dos lucros para financiar seu processo de expansão. A equação (29) pode ser combinada com a equação (25), que representa a taxa de lucro como função da taxa de capacidade de utilização, e isolar a variável $g$. O resultado é a equação (30), que descreve a taxa de acumulação da economia compatível com a poupança obtida a partir dos parâmetros e das variáveis do termo à direita da referida equação.

$$
g^{s}=s_{c} m u / k(1-x)
$$

Portanto, com o uso da condição de equilíbrio de investimento igual a poupança, pode-se igualar as equações (27) e (29) de forma a obter a equação (31) e determinar a taxa de acumulação $g$ " de steady state.

$$
g^{*}=\gamma s_{c} /\left[s_{c}-\left(\frac{k}{m}\right)(1-x) g_{u}\right]
$$

Essa equação determina a taxa de acumulação de steady state e pode ser visualizada na Figura 4 (Lavoie, 1998, p.426), que mostra o equilíbrio das equações de investimento e de poupança com o fechamento neo-kaleckiano do modelo do NTP, de forma à especificação da função investimento incorporar a variável taxa de utilização da capacidade. Como é usual nos modelos neo-kaleckianos, a condição de estabilidade do sistema é que o parâmetro $s_{c}$ assume um valor suficientemente grande para garantir que o denominador da equação (31) seja positivo. Adicionalmente deve ser assumido que o parâmetro $\gamma$ deve ser positivo para $g^{*}$. 


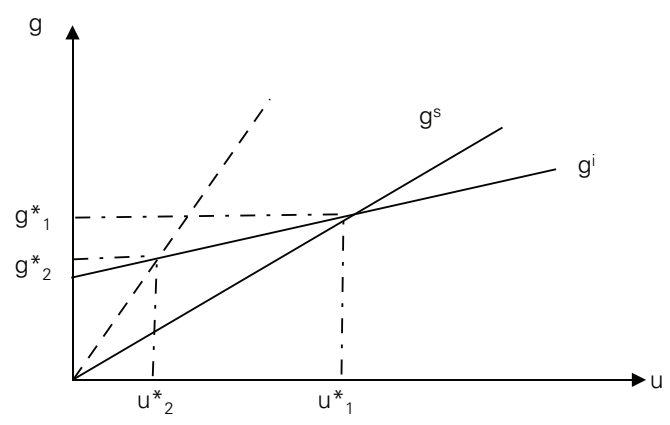

A análise estática de equilíbrio do NTP que o deslocamento da função poupança para cima da sua posição original, em razão da elevação da taxa de retenção $s_{c}$ ou da proporção de financiamento externo $x$, ocasionará uma queda da taxa de acumulação de steady state, como pode ser visto na Figura 4. Isto ocorre pelo canal de contração da demanda efetiva. Da mesma forma, uma elevação da margem de lucro $m$ vai também deslocar a curva $g_{s}$ para a esquerda, portanto, com redução da taxa de utilização e de acumulação. Ou seja, obtém-se o resultado kaleckiano clássico de que a elevação da participação dos salários na renda impacta positivamente a taxa de lucros das empresas por meio da elevação da demanda agregada. Esses resultados são obtidos de forma que o NTP continue válido.

Em síntese, Lavoie (1998, p.429) defende que a introdução da taxa de valorização $v$ não afeta o resultado keynesiano básico no sentido da causalidade do investimento para poupança; assim como o resultado kaleckiano canônico de que a elevação da participação dos salários na renda aumenta a taxa de lucro. Nesse sentido, a crítica de Davidson não se sustentaria: a introdução da variável $v$ não seria uma concessão à teoria econômica neoclássica, pois mesmo que as firmas tenham um comportamento em relação à sua estrutura de capital determinado pela taxa q-Tobin, o regime de crescimento Neo-Pasinetti manteria os resultados keynesianos fundamentais.

Entretanto, Lavoie qualifica o caso em que a função de investimento neo-kaleckiana é especificada com a variável $v$. Nessa situação, a mudança da propensão a poupar das famílias poderia afetar a taxa de acumulação, pois a mudança desse parâmetro aumentaria a variável $v$ que poderia impactar a taxa de acumulação $g$. Nesse sentido, o ponto importante do debate passa a ser a especificação da função investimento, como se discute na próxima seção.

\section{SKOTT E A ESPECIFICAÇÃO DA FUNÇÃO INVESTIMENTO NOS MODELOS NEO-KALECKIANOS}

Os modelos neo-kaleckianos de crescimento e distribuição de renda, nos quais o grau de utilização da capacidade produtiva é a variável de ajuste entre as deci- 
sões de poupança e investimento, se tornaram dominantes na macroeconomia pós-keynesiana nos últimos 30 anos (Skott, 2010, p.108). Uma característica fundamental desses modelos é que a resposta do investimento a variações no grau de utilização da capacidade produtiva é baixa e constante ao longo do tempo. Em particular, a sensibilidade de curto prazo da taxa de acumulação de capital às variações do grau de utilização da capacidade produtiva é tida como igual à sensibilidade de longo prazo daquela variável. No curto prazo é razoável supor que o investimento é relativamente pouso sensível ao grau de utilização da capacidade produtiva, sendo essa baixa sensibilidade, inclusive, uma condição necessária para a estabilidade do equilíbrio de curto prazo nos modelos neo-kaleckianos ${ }^{7}$. Mas essa é uma hipótese inaceitável para o longo prazo, uma vez que variações na demanda agregada têm, em geral, efeitos defasados sobre o investimento, o que irá atuar no sentido de aumentar a sensibilidade de longo prazo da acumulação de capital ao nível de utilização da capacidade produtiva (Ibidem, p.112-113).

A baixa sensibilidade da taxa de acumulação de capital às variações do grau de utilização da capacidade produtiva no longo prazo não é apenas uma hipótese comportamental pouco plausível, como ainda gera problemas sérios de calibragem para os modelos neo-kaleckianos. Com efeito, assumindo-se os valores de referência utilizados nos modelos neo-kaleckianos para os parâmetros, verifica-se que em tais modelos o grau de utilização da capacidade produtiva mostra-se hipersensível às variações dos valores dos parâmetros, particularmente às variações na propensão a poupar.

Para entender esse ponto consideremos a versão do modelo neo-kaleckiano desenvolvida por Amadeo (1987).

$$
\begin{aligned}
& \sigma=\frac{S}{K}=s_{c} \pi u \sigma \\
& g=\frac{I}{K}=f+h\left[u-u^{n}\right] \\
& g=\sigma
\end{aligned}
$$

Onde: $s_{c}$ é a propensão a poupar a partir dos lucros; $\pi$ é a participação dos lucros na renda, $u$ é o grau de utilização da capacidade produtiva e $\sigma$ é a produtividade do capital; $u^{n}$ é o grau normal de utilização da capacidade produtiva; $f$ representa o componente autônomo do investimento, determinado pelo animal spirits dos empresários e $b$ mede a sensibilidade do investimento às divergências entre o grau efetivo e normal de utilização da capacidade produtiva.

A equação (32) apresenta a poupança desejada como proporção do estoque

\footnotetext{
${ }^{7}$ Mais especificamente, para que o equilíbrio de curto prazo seja estável é necessário que a sensibilidade da poupança desejada às variações do grau de utilização da capacidade produtiva seja maior que a sensibilidade do investimento com relação a mudanças nessa variável.
} 
de capital (função poupança), a equação (33) apresenta a taxa desejada de crescimento do estoque de capital (função investimento); ao passo que a equação (34) representa a condição de equilíbrio no mercado de bens.

Substituindo (32) e (33) em (34), obtemos o nível de utilização da capacidade produtiva de equilíbrio do modelo. Temos que:

$$
u^{*}=\frac{f-h u^{n}}{s_{c} \pi \sigma-h}
$$

A equação (35) define o nível de utilização da capacidade produtiva que garante o equilíbrio no mercado de bens. Para que $u^{*}>0$ é necessário que $\left(s_{c} \pi \sigma-h\right)$, ou seja, que a sensibilidade da poupança às variações do grau de utilização da capacidade produtiva seja maior que a sensibilidade do investimento às variações dessa mesma variável. Trata-se da condição-padrão para assegurar a existência e a estabilidade do equilíbrio macroeconômico em modelos neo-kaleckianos de crescimento (Skott, 2010, p.110).

Uma vez determinado o grau de utilização da capacidade produtiva de equilíbrio, podemos facilmente determinar a taxa de crescimento do estoque de capital ao substituir a equação (35) em (33). Nesse caso, temos:

$$
g^{*}=\frac{f-h u^{n}}{\left[1-\left(\frac{h}{s_{c} \pi \sigma}\right)\right]}
$$

$\mathrm{Na}$ equação (36) observamos que a taxa de crescimento do estoque de capital que garante o equilíbrio macroeconômico é uma função (i) do investimento autônomo; (ii) do grau normal de utilização da capacidade produtiva; (iii) da participação dos lucros na renda; (iv) da propensão a poupar a partir dos lucros e (v) da produtividade do capital.

Um resultado importante do modelo refere-se ao efeito de um aumento da propensão a poupar a partir dos lucros sobre a taxa de acumulação de capital. Uma simples inspeção da equação (36) revela que um aumento da propensão a poupar a partir dos lucros irá reduzir a taxa desejada de acumulação de capital. Um aumento da propensão a poupar a partir dos lucros irá resultar, para o nível inicial de utilização da capacidade produtiva, num aumento da taxa de poupança. Isso significa uma redução das vendas ou do seu ritmo de crescimento. Confrontadas com uma queda das vendas, as empresas irão reduzir a produção, fazendo com que o nível de utilização da capacidade produtiva se reduza, ou seja, ampliando o nível de capacidade excedente. $\mathrm{O}$ aumento da capacidade ociosa irá desestimular as decisões de investimento, fazendo com que a taxa desejada de acumulação de capital se reduza.

Esse segundo resultado pode ser visualizado por intermédio da Figura 5 onde apresentamos a taxa desejada de acumulação de capital e o grau de utilização da capacidade como função de diversos valores para a propensão a poupar a partir 
dos lucros. Para essa simulação consideremos os seguintes valores para os parâmetros: $f=0,02 ; \pi=0,4 ; \sigma=0,5 ; u^{n}=0,85 ; h=0,01$.

Figura 5: Taxa de Acumulação de Capital, Utilização da Capacidade

e Propensão a Poupar a partir dos Lucros

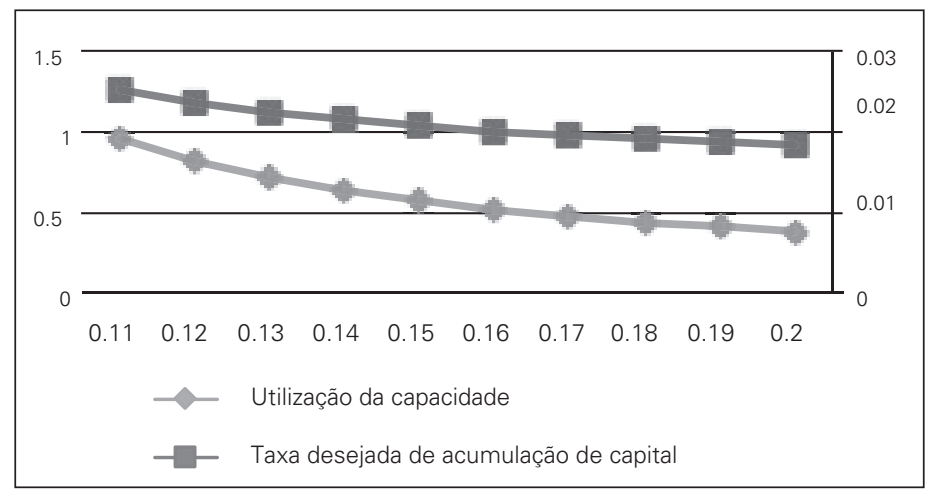

Fonte: Elaboração dos autores.

Conforme podemos visualizar na Figura 5 acima, o grau de utilização da capacidade produtiva de equilíbrio é extremamente sensível a variações da propensão a poupar a partir dos lucros. O mesmo não ocorre, contudo, com a taxa desejada de acumulação de capital. Enquanto um aumento de $81,81 \%$ da propensão a poupar (de 0,11 para 0,20 ) resulta numa queda de $60 \%$ do grau de utilização da capacidade produtiva, a taxa de acumulação de capital se reduz apenas $27,2 \%$. Nas condições da simulação, o grau de utilização da capacidade produtiva é 2,2 vezes mais sensível a um choque na função poupança do que a taxa de acumulação de capital. Trata-se de uma propriedade intrínseca dos modelos neo-kaleckianos de crescimento que aparentemente não é consistente com as magnitudes observadas das variações dessas variáveis no mundo real ${ }^{8}$.

Esses ressultados levaram Skott (2010) a concluir que:

"From a theretical perspective the problem with the Kaleckian specifications arise from the combination of an exogenous markup with the extension to the long run of a standard keynesian short-run stability condition: the relative insensivity of investment to variations in agregate demand. A Harrodian approach address these issues"(Ibidem, p.111-112).

No que consiste a abordagem harrodiana para a questão da especificação da função investimento? Seguindo Skott (2010), o ponto central dessa abordagem é fazer uma distinção entre os efeitos de curto e longo prazo de variações da demanda agregada e, por conseguinte, do nível de utilização da capacidade produtiva sobre a

${ }^{8}$ A esse respeito ver Skott (2010). 
taxa desejada de acumulação de capital. Mais especificamente, deve-se supor que o efeito de longo prazo é maior que o efeito de curto prazo. Uma maneia simples de formalizar essa ideia é supor que a variação da taxa de acumulação de capital é uma função da divergência entre os níveis efetivo e esperado de utilização da capacidade produtiva, conforme a equação (37) abaixo (Skott e Ryoo, 2008, p.840):

$$
\frac{d}{d t} \widehat{K}=\mu\left(u-u^{*}\right) ; \mu>0
$$

Onde: $\widehat{K}$ é a taxa de crescimento do estoque de capital; $u$ é o grau efetivo de utilização da capacidade produtiva e $u^{*}$ é o grau desejado ou normal de utilização da capacidade produtiva.

Nas palavras de Skott (2010, p.113):

"The standard Harrodian specification [...] implies that the accumulation rate becomes a state variable and that there is no immediate impact of changes in utilization on investment. In the long run, by contrast, accumulation is perfect elastic. Utilization must be at the desired rate in steady growth, but as long as this condition is satisfied, the accumulation function imposes no constraints on the growth rate."

Quais as implicações da crítica de Skott para o NTP? Como vimos na seção anterior, a solução dada por Lavoie para a crítica de Davidson deixava em aberto a determinação da taxa de acumulação de capital, ou seja, deixava o modelo indeterminado. A maneira de resolver essa indeterminação é acrescentar na estrutura do modelo de Lavoie uma equação para a taxa de acumulação de capital para "fechar" o modelo. O "fecho" de Lavoie é precisamente a função de acumulação neo-kaleckiana [ver equação (29)]. O problema é precisamente que essa especificação não só não possui uma adequada fundamentação teórica, como ainda gera um padrão de comportamento para o grau de utilização da capacidade produtiva e para a taxa de acumulação de capital que não guardam a mínima correspondência com o mundo real. Ao se substituir a especificação neo-kaleckiana pela especificação harrodiana, a taxa de acumulação de capital fica novamente indeterminada, fazendo com que a versão de Lavoie no NTP apresente um claro problema de indeterminação de variáveis endógenas.

\section{CONSIDERAÇÕES FINAIS}

Ao longo deste artigo procuramos avaliar a robustez teórica do assim chamado Novo Teorema de Pasinetti, segundo o qual numa economia na qual a diferenciação entre as propensões a poupar a partir dos lucros e dos salários deve-se a natureza da renda empresarial, não a filiação a uma classe social específica; a taxa de lucro ao longo da trajetória de crescimento de Golden Age é independente da propensão a poupar dos trabalhadores, sendo determinada pelo coeficiente de reten- 
ção de lucros das firmas, pela fração do investimento que as empresas desejam financiar com recursos de terceiros e pela taxa natural de crescimento.

A formulação original do NTP por Kaldor (1966) foi criticada por Davidson (1968), para quem essa formulação estaria recuperando o papel da taxa de juros (por intermédio da taxa de valorização das obrigações, $v$ ) como mecanismo de coordenação entre as decisões de poupança e investimento ao nível de renda de pleno emprego.

A crítica de Davidson levou Lavoie (1998) a reapresentar o NTP no contexto dos modelos neo-kaleckianos de crescimento e distribuição de renda, desenvolvidos no início dos anos 1980. Nesse contexto, Lavoie (Ibidem, p.429) argumenta que a introdução da taxa de valorização dos títulos emitidos pelas empresas $v$ não afeta o resultado keynesiano básico no sentido da causalidade do investimento para poupança, assim como o resultado neo-kaleckiano básico de que a elevação da participação dos salários na renda aumenta a taxa de lucro.

Por fim, a solução de Lavoie (1998) para o NTP gerou, mais recentemente, um debate a respeito da especificação da função investimento. Os modelos neo-kaleckianos assumem que o ritmo de acumulação de capital é pouco sensível às divergências entre o grau efetivo e desejado de utilização da capacidade produtiva. Essa baixa sensibilidade da acumulação de capital faz, contudo, que o grau de utilização da capacidade produtiva seja hipersensível às variações dos parâmetros do modelo, particularmente às variações na propensão a poupar (Skott, 2010).

Nesse contexto, a especificação teórica mais adequada para a função investimento é a harrodiana, cuja característica central é supor que o efeito de longo prazo das variações do grau de utilização da capacidade produtiva sobre a taxa de acumulação de capital é maior que o efeito de curto prazo.

A partir da crítica de Skott verificamos que a formulação de Lavoie para o NTP envolve um claro problema de indeterminação das variáveis endógenas do modelo de crescimento e distribuição por ele apresentado.

\section{REFERÊNCIAS BIBLIOGRÁFICAS}

Amadeo, E.J. (1987). "Expectativas, demanda efetiva e centros de gravitação”. In Lopes, C., org, Ensaios de Economia Pós-Keynesiana. Imprensa Universitária. Universidade Federal do Ceará.

Davidson, P. (1968). "The demand and supply of securities and economic growth and its implications for the Kaldor-Pasinetti controversy". American Economic Review, v. LVIII, n. 2, pp. 252-269.

Harcourt, G.C. (1972). Some Cambridge Controversies in the Theory of Capital. Cambridge: Cambridge University Press.

Kaldor, N. (1966). "Marginal productivity and macroeconomic theories of distribution: comment on Samuelson and Modigliani". Review of Economic Studies, v.33, n.4, pp. 309-319.

Kaldor, N. (1956). “Alternative theories of distribution”. Review of Economic Studies, v.23, n.2, pp. 83-100.

Lavoie, M. (1998). "The Neo-Pasinetti Theorem in Cambridge and Kaleckian models of growth and distribution”. Eatern Economic Journal, v.24, n.4, pp. 417-434.

Lima, G.T. (2004). "Whose saving behavior really matters in the long-run?” Nova Economia. v.13, n.2, pp. 11-36. 
Oreiro, J.L. (2016) Macroeconomia do Desenvolvimento: Uma Perspectiva Keynesiana. Rio de Janeiro: LTC Editora.

Oreiro, J.L. (2005). “Uma revisão das controvérsias sobre a Equação de Cambridge”. Nova Economia, v.15, n. 2, pp. 119-149.

Meade, J. (1963). "The rate of profit in a growing economy". The Economic Journal, v.73, n.292, pp. 665-674.

Meade, J. (1966). "The outcome of the Pasinetti process: a note". The Economic Journal, v.76, n.301, pp. 161-165.

Pasinetti, L. (1962). "Rate of profit and income distribution in relation to the rate of economic growth". The Review of Economic Studies, v.29, n.4, pp. 267-279.

Pasinetti, L. (1966). "New results in an old framework: comment on Samuelson and Modigliani". The Review of Economic Studies, v. 33, n.4, pp. 303-306.

Pasinetti, L. (1974). "The rate of profit in an expanding economy" in Growth and Distribution: Essays in Economic Theory. Cambridge: Cambridge University Press.

Pasinetti, L. (1989). "Ricardian debt/taxation equivalence in the Kaldor theory of profits and income distribution". Cambridge Journal of Economics, 13, pp.25-36.

Rowthorn, B. (1981). "Demand, real wages and economic growth". Thames Papers in Political Economy, autumn, TP/PPE/81/3.

Samuelson, P; Modigliani, F. (1966). "Reply to Pasinetti and Robinson". The Review of Economic Studies. v. 33, n.4, pp. 321-330.

Skott, P. (2010) "Growth, instability and cycles: Harrodian and Kaleckian models of accumulation and income distribution" In: Setterfield, M. (org.). Handbook of Alternative Theories of Economic Growth. Edward Elgar: Aldershot.

Skott, P; Ryoo, S. (2008). "Macroeconomic implications of financialisation". Cambridge Journal of Economics, 32(6), pp. 827-862.

Townsend, H. (1937). "Liquidity premium and the theory of value". The Economic Journal, v.47, n.185, pp. 157-169. 